Brit. J. industr. Med., 1961, 18, 148.

\title{
THE EFFECTS OF VOLE BACILLUS VACCINATION OF AFRICAN MINE WORKERS IN THE NORTHERN RHODESIAN COPPER MINES
}

\author{
BY \\ R. PAUL \\ From the Pneumoconiosis Medical and Research Bureau, Kitwe, Northern Rhodesia
}

(RECEIVED FOR PUBLICATION AUGUST 31, 1960)

\begin{abstract}
African mine workers exposed to siliceous dust in the metalliferous mines of Northern Rhodesia were tuberculin tested; of 17,697 tested, 13,667 were tuberculin positive and 4,030 negative. The negative reactors were divided at random into two approximately equal groups and 1,984 were vaccinated with vole bacillus vaccine and 2,046 were left unvaccinated. These two groups were subsequently followed up and their original radiological categories at the time of tuberculin testing and vaccination were compared with their radiological categories after varying periods of further dust exposure. The object of the investigation was to ascertain whether or not vaccination with vole bacillus vaccine introduced an accelerating factor in the rate of radiological change in pneumoconiosis. The results of the investigation showed that radiological changes in the two groups were minimal and that there was virtually no difference between them. No accelerated changes were recorded in the negative vaccinated group. This is regarded as evidence that anti-tuberculosis vaccine does not introduce an accelerating factor in pneumoconiosis.

No case of pulmonary tuberculosis occurred in the negative vaccinated group. Three cases were recorded in the negative non-vaccinated group, suggesting that vaccination with vole bacillus vaccine affords some measure of protection against tuberculosis, and in view of the absence of any evidence that it had an accelerating effect in pneumoconiosis it appears desirable that miners should receive this protection.
\end{abstract}

Massive fibrosis is accepted by many as being a modified form of pneumoconiosis, characterized by excessive fibrosis due to the combined action on the lung of a low-grade infection and the specific dust causing the pneumoconiosis. We believe, with other workers in the field of pneumoconiosis, that this infective element is tuberculous (Gough, 1947; Fletcher, 1948; Heppleston, 1951; Cochrane, 1954; James, 1954).

Animal experimental studies especially those of King (1957) and Byers and King (1959) have shown that the intratracheal administration of attenuated tubercle bacilli (vole or B.C.G.) and dust, administered either intratracheally or by inhalation, produces lesions resembling the progressive massive fibrosis seen in industrial workers' pneumoconiosis.

Although there is little similarity between the very large dose of vole bacilli and dust introduced intratracheally into the lungs of animals in these experiments and the very small dose of vole bacilli given intracutaneously in vaccination, nevertheless the advisability of vaccinating workers who have dust fibrosis or who are exposed to that hazard is not universally accepted in view of the theoretical possibility that in so doing a potential accelerating factor may be introduced.

This paper gives an account of the effect of vaccinating with vole bacillus vaccine African mine workers who had been exposed to siliceous dust both before and after vaccination. The vaccination was carried out as an independent research by the Tuberculosis Research Association, Kitwe, under the direction of Dr. Honor Smith and Dr. R. L. Vollum of the Radcliffe Infirmary, Oxford. A full account of this investigation will be published in due course. Its object was to assess the value of vole bacillus vaccine in an African population which included, inter alia, African mine workers of four of the major copper mines of Northern Rhodesia 
who were subject to the provisions of the Pneumoconiosis Ordinance of Northern Rhodesia implemented by the Pneumoconiosis Medical and Research Bureau.

Brief History of Pneumoconiosis Legislation, the Medical Bureau and the Mines of Northern Rhodesia

Pneumoconiosis legislation in Northern Rhodesia was first enacted in 1945, and established the Pneumoconiosis Medical and Research Bureau. The Bureau, a government institution, is staffed by full-time medical officers and is equipped to carry out all chest and ancillary diagnostic procedures. There is also a fully equipped pathological laboratory and facilities for animal experimental studies. The Pneumoconiosis Ordinance of Northern Rhodesia demands that every European and African mine worker must hold a valid certificate of fitness issued by the Bureau before he is permitted to work in an occupation with a pneumoconiosis hazard. The issue of a certificate for engagement (initial certificate) is dependent upon the prospective employee passing a clinical examination and a radiological examination of his chest on a full-size film. Thereafter he must attend at yearly intervals for further examination (periodical certificate) at which a further clinical and radiological examination on a full-size film is carried out. On leaving mining he is finally clinically and radiologically examined (discharge examination). The average number of mine workers examined each year is 5,000 Europeans and 35,000 Africans.

Small deposits of copper oxide ore have been mined intermittently in Northern Rhodesia since 1910. Large deposits of sulphide ore were known to exist, but it was not until the flotation process was developed that they could be worked profitably. When this process was perfected, large-scale development began in 1926 and the first production took place in 1929. From this beginning six major mines have been developed which produced more than 500,000 tons of copper in 1959, making Northern Rhodesia the second largest copper producing country in the world.

Dust sampling on these mines is the joint responsibility of the Government Mines Department and the ventilation departments of each mine. The Mines Department uses thermal precipitators and Hexhlet apparatus and the ventilation departments of the mines employ the Rand Konimeter for " snap sampling". The agreed maximum permissible limit of dust particles between 0.4 and $7.0 \mu$ is 350 per ml., but in fact counts in most operations are lower than this. The free silica content of this fine atmospheric dust is determined by the $x$-ray diffraction method using the Geiger counter technique; the average free silica content of the atmospheric dust in the above range in the four mines taking part in this investigation is Mine $\mathrm{A}$ : $43 \%$; Mine B: $28 \%$; Mine C: $23 \%$ and Mine D: $19 \%$ African mine workers from these four mines constitute the population on which our observations have been made.

\section{Tuberculin Testing and Vaccination}

Purified protein derivative (P.P.D.) in a concentration of $2 \mathrm{mg}$. per $\mathrm{ml}$. was used in the tuberculin testing. This was obtained from the Veterinary Laboratory of the Ministry of Agriculture and Fisheries, Weybridge, Surrey. One minim of $1 / 100$ adrenalin was added to $1 \mathrm{ml}$. of P.P.D. and the tuberculin was applied to the cleansed skin of the flexor aspect of the forearm by means of a glass rod. The tuberculin test was made with East's modification of the Heaf multiple puncture apparatus set at a penetrating depth of $2 \mathrm{~mm}$. The reaction was read 72 hours later. The negative reactors were divided at random into two approximately equal groups, one receiving the vaccine and the other remaining unvaccinated.

The programme of testing was as follows: Mine A, January to February 1956; Mine B, September to October 1954; Mine C, April to July 1954; Mine D (this constituted the largest number, therefore tuberculin testing was spread over two main periods): D1, November 1952 to January 1953; D2, December 1954 to February 1955. Vole bacillus vaccine was administered by means of a Birkhaug multiple puncture machine (40 needles) set at a penetrating depth of $2 \mathrm{~mm}$.; the site of inoculation was the left upper arm above the deltoid insertion. Vaccination was carried out immediately after tuberculin testing and took place during the same periods as specified in the tuberculin testing programme.

\section{Radiological Classification}

The radiological classification used to describe the classical silicosis encountered in the copper mines of Northern Rhodesia and used to describe the radiological changes in this investigation is as follows:

" $\mathrm{O}$ " (Normal). Normal thorax.

"I" (Indeterminate). In this category there is a general increase in the lung marking of indeterminate cause.

" L" (Linear). This category is characterized by the presence of numerous fine linear lung markings usually tending to obscure the normal pulmonary vascular pattern and sometimes associated with enlargement of the hilar glands.

" $\mathrm{N}$ " (Nodular). This category is characterized by the presence of nodular opacities and is subdivided into three depending on the size and profusion of the nodules. 
TABLE 1

SUMMARY OF RESULTS, WITH CHANGES IN RADIOLOGICAL CATEGORY

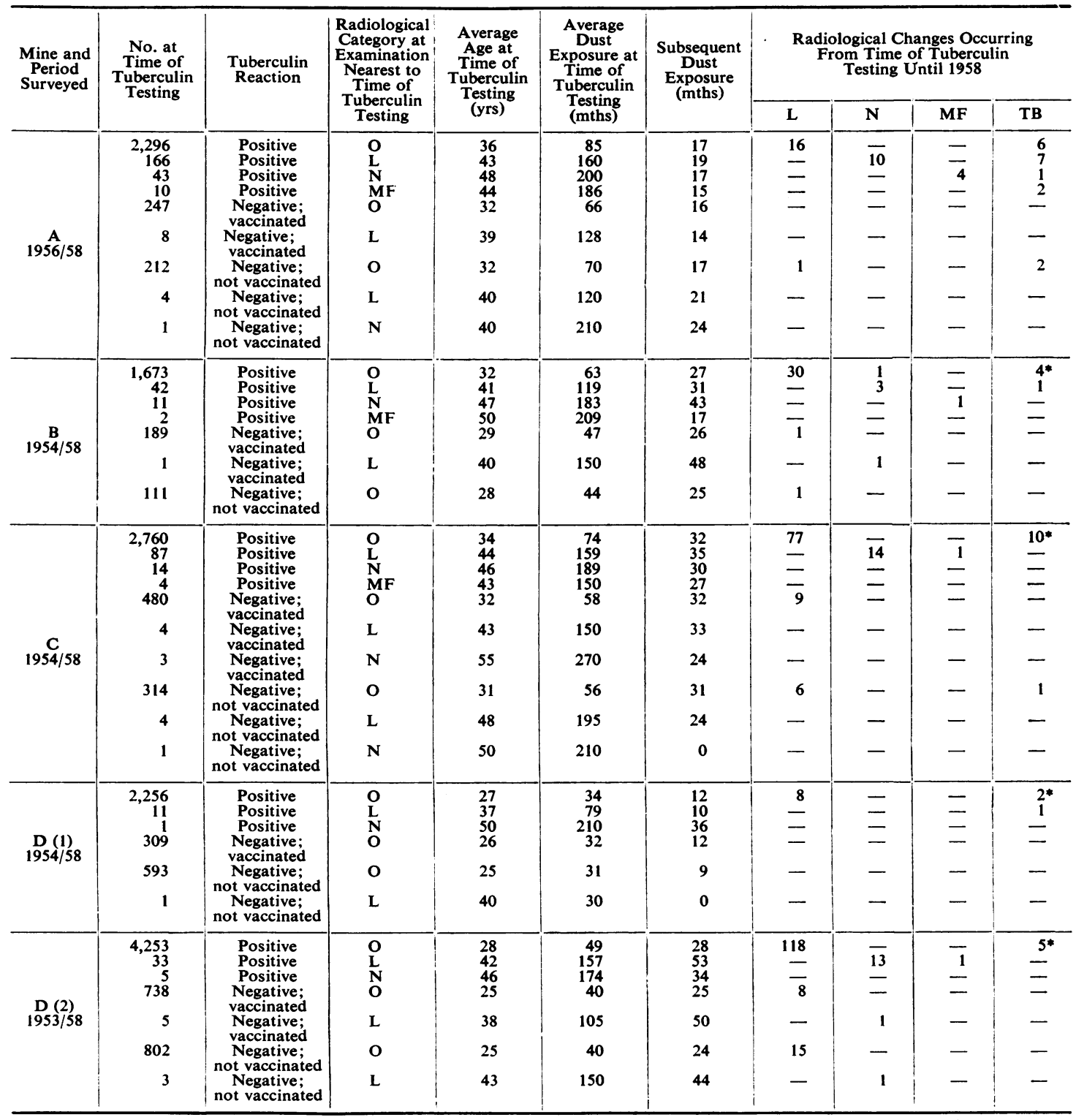

* Includes one pleural effusion (positive culture).

"IN" (Infective nodular). In this category the nodules are characterized by their irregular outline, variation in size and density and their tendency to coalesce. It is similarly sub-divided depending on the size and profusion of the nodules.
" MF" (Massive Fibrosis). This category is characterized by the presence of dense fibrosis which is usually non-homogeneous and which has an irregular outline. It is also sub-divided into three according to the extent of the lung fields occupied by the dense fibrosis. 
"ST" (Silico-tuberculosis). In this category overt tuberculosis has been superimposed on a background of dust fibrosis.

“TB" (Tuberculosis). Simple pulmonary tuberculosis.

\section{Investigation}

In all, 17,697 mine workers took part in the investigation and were tuberculin tested. 13,667 were found to be tuberculin positive, and 4,030 tuberculin negative. The latter were divided at random into two approximately equal groups of whom 1,984 were vaccinated and 2,046 remained unvaccinated. The three groups were analysed at the end of 1958 for any radiological changes that had occurred from the time of original tuberculin testing and vaccination. The radiological examination done at the Bureau nearest to the time of tuberculin testing was recorded in each case and the radiological category at that time was compared with that of subsequent radiological examinations and, finally, with the examination nearest to December 31, 1958.

The films were classified with a knowledge of their dates, but without knowledge of the tuberculin sensitivity of the miner, or whether he had or had not been vaccinated.

\section{Results}

The radiological changes are summarized in Table 1.

\section{Discussion}

It was not possible to follow up all the mine workers from each mine for the same period of time due to the fact that a proportion of them had left the mines during the follow-up period and were not available for final examination in 1958. Table 2 shows the number of mine workers originally participating in the investigation and the percentage who were finally examined in 1958 .

These percentages, it will be seen, vary between the mines and to a very much lesser degree between the three groups of positive, negative vaccinated, and negative not-vaccinated at each mine. The reason for this is to be found in the rate at which African mine workers leave the industry. In a previous investigation (Paul, 1959) it was found that approximately $60 \%$ of all new African entrants to the industry left within the first two years. This rapid rate of leaving declines after the first few years of mining service. Mine $\mathrm{D}$ had an abnormally large number of these new entrants compared with the other mines, and had a greater discharge rate. The fact that only a percentage of each group was followed up until the end of 1958 may have
TABLE 2

NUMBERS OF MINE WORKERS PARTICIPATING AND PERCENTAGES EXAMINED IN 1958

\begin{tabular}{|c|c|c|c|c|}
\hline \multirow{2}{*}{\multicolumn{2}{|c|}{$\begin{array}{l}\text { Mine and } \\
\text { Year of } \\
\text { Original } \\
\text { Testing }\end{array}$}} & \multicolumn{3}{|c|}{$\begin{array}{l}\text { Number of Original Mine Workers and (in brackets) } \\
\text { the Percentage Examined in } 1958\end{array}$} \\
\hline & & Positive & $\begin{array}{l}\text { Negative: } \\
\text { Vaccinated }\end{array}$ & $\begin{array}{c}\text { Negative: } \\
\text { Not Vaccinated }\end{array}$ \\
\hline $\begin{array}{l}\text { A } \\
\text { B } \\
\text { C } \\
\text { D1 } \\
\text { D2 }\end{array}$ & $\begin{array}{l}1956 \\
1954 \\
1954 \\
1954 \\
1953\end{array}$ & $\begin{array}{l}2,515(76 \%) \\
1,728(52 \%) \\
2,865(65 \%) \\
2,268(21 \%) \\
4,291(35 \%)\end{array}$ & $\begin{array}{l}255(75 \%) \\
190(56 \%) \\
487(63 \%) \\
309(18 \%) \\
743(31 \%)\end{array}$ & $\begin{array}{l}217(80 \%) \\
111(55 \%) \\
319(63 \%) \\
594(19 \%) \\
805(28 \%)\end{array}$ \\
\hline
\end{tabular}

introduced a bias. But this is considered unlikely in that at each mine both negative groups had approximately the same percentage of miners examined in 1958, and this would imply that the men of the vaccinated and not-vaccinated groups, who left in the intervening years, did so for similar reasons. Analysis of the radiographs of those who did leave in the intervening years shows that all did so with an unchanged radiological category, and from this it is deduced that the reasons for leaving were the customary ones, e.g. unsuitability for and lack of adaptability to underground conditions.

Reference to the Tables shows that the major radiological changes took place in the tuberculin positive group. This is to be expected as this group consisted of older mine workers who, consequently, had had considerably more dust exposure than those in the two negative groups. The primary concern of the investigation was, however, a comparison between the two negative groups, and it will be seen that the radiological changes recorded in both groups were minimal and that there was virtually no difference between them. None in either negative group developed massive fibrosis or the infective type of nodulation, and there were no accelerated radiological changes recorded in the negative vaccinated group. These findings are regarded as evidence that vaccination with vole bacillus vaccine had no accelerating influence on pneumoconiosis. Further, the three cases of pulmonary tuberculosis recorded in the negative reactors all occurred in the negative non-vaccinated group and, although the number is small, it suggests that the vaccine gave some measure of protection against pulmonary tuberculosis.

\section{Conclusion}

In view of the absence of any evidence that vole bacillus vaccine has an accelerating influence in pneumoconiosis, and because of the apparent protective value it has against tuberculosis, it appears desirable that it or other protective anti- 
tuberculosis vaccine should be given to tuberculin negative reactors entering an industry with a pneumoconiosis hazard.

I am indebted to Dr. Honor Smith and Dr. R. L. Vollum of the Radcliffe Infirmary, Oxford. I also wish to thank Mr. G. Addison, B.Sc. (Econ.), Statistician to the Bureau, for his assistance.
REFERENCES

Byers, P. D., and King, E. J. (1959). Lab. Invest., 8, 647. Cochrane, A. L. (1954). Brit. J. Tuberc., 48, 274. Fletcher, C. M. (1948). Brit. med. J., 1, 1015. Gough, J. (1947). Occup. Med., 4, 86. Heppleston, A. G. (1951). A.M.A. Arch. industr. Hyg., 4, 270.

James, W. R. L. (1954). Brit. J. Tuberc., 48, 89.

King, E. J. (1957). In Reports, 12th International Congress on Occupational Health, Helsinki, 1957, Vol. 1, p. 283.

Paul, Rational (1959). Northern Rhodesia Preumoconiosis Medical and Research Bureau Annual Report for Year 1959. Government Printer, Lusaka.

\section{THE JANUARY (1961) ISSUE}

The January (1961) issue contains the following papers:-

Background to Byssinosis in Ulster. By James A. Smiley.

Pulmonary Fibrosis in Workers Exposed to Finely Powered Aluminium. By John Mitchell, G. B. Manning, M. Molyneux, and Ronald E. Lane.

Pulmonary Fibrosis in a Worker Using an Aluminium Powder. By J. Warren Jordan.

Bronchitis-Sickness Absence in London Transport. By C. J. Cornwall and P. A. B. Raffle.

The Causes of Death in Iron and Steel Workers (Non-foundry). By A. I. G. McLaughlin and H. E. Harding.

A Study of Aspergillus Spores in the Atmosphere of a Modern Mill. By F. C. Stallybrass.

Christmas Disease and Coal-mining. By C. B. Kerr.

Methyl Bromide Poisoning. By E. M. Rathus and P. J. Landy.

Coproporphyrinuria in Groups of Workers as an Index of Inorganic Lead Absorption. By R. L. Zielhuis

Erosion of the Teeth Due to Sulphuric Acid in the Battery Industry. By D. Malcolm and E. Paul.

Observations on the Urinary Protein of Men Exposed to Cadmium Dust and Fume. By J. C. Smith, Agnes R. Wells, and J. E. Kench.

Miscellanea

Book Reviews

A number of copies are still available and may be obtained from the Publishing Manager, British Medical Association, Tavistock Square, W.C.1, price 17s. $6 d$. 